\title{
Power Distance and Verbal Index in Kazakh Business Discourse
}

\author{
Buadat Karibayeva (Corresponding author) \\ Kazakh Ablai khan University of International Relations and World Languages, 050000, Almaty, The Republic of Kazakhstan \\ E-mail: buadat@gmail.com \\ Salima S. Kunanbayeva \\ Kazakh Ablai khan University of International Relations and World Languages, 050000, Almaty, The Republic of Kazakhstan
}

Received: 11-09-2016

Published: 01-03-2017
Accepted: 07-11-2016

doi:10.7575/aiac.ijalel.v.6n.2p.8
Advance Access Published: January 2017

URL: http://dx.doi.org/10.7575/aiac.ijalel.v.6n.2p.8

\begin{abstract}
Kazakh business discourse is a relatively new area for research, and hence many of the cultural preferences are yet to be explored. This paper focuses on measuring Hofstede's power distance index for Kazakh culture. A novel technique is proposed, where verbal index is calculated from analysis of publically available texts delivered by representatives of different cultures. In particular, we analyzed public speeches delivered by leaders of New Zealand, UK, Germany, Australia, USA, Greece, China, India, and Kazakhstan. From these texts we derived a verbal index, which closely correlated to Hofstede's power distance data. As a result, we were able to obtain a power distance index of 58 for Kazakhstan, which was previously unavailable in literature. Furthermore, this method can be used as a cheaper alternative to conducting surveys in estimating Hofstede's power distance indexes for different cultures.
\end{abstract}

Keywords: Power distance, business discourse, language context

\section{Introduction}

Understanding cultural preferences within a workplace can be vital for successful operation of any multinational business venture. This can be of particular interest for corporations entering new markets, and hence it is of great practical importance for international oil and mineral exploration and production companies expanding in Kazakhstan over the past few decades. Fortunately, cultural preferences and resulting implications within workspace environment are actively researched by academic community, and quantitative measures of cultural preferences like power distance index were developed and validated.

Originally power distance index was proposed by Hofstede in his cultural dimensions theory (Hofstede, 1980). Power distance measures a degree to which less powerful members of organizations can accept uneven distribution of power. This is applicable not only within corporate structures but also within communities as a whole. Hofstede conducted a survey of IBM employees across the globe and used the data to explore variations in cultural values. Hofstede argued that any culture can be classified using individualism-collectivism, masculinity-femininity, uncertainty avoidance, and power distance. The latter parameter in particular is useful in interpreting cultural preferences within multicultural organizations, and can be potentially used to adjust management strategies. As a result, the concept of power distance has been actively researched over past few decades.

Bochner and Hesketh (1994) validated Hofstede's power distance theory in a single multicultural work setting, where 263 workers from 28 countries participated in the study. People from Anglo-Celt cultural groups scored lower on power distance index, as originally predicted by Hofstede. Moreover, responders from non-Anglo-Celt groups reported greater number of discrimination incidents and favored cultural diversity in the work place (Bochner \& Hesketh, 1994).

Brockner et al. (2001) studied the implications of power distance within cultural and procedural justice context. Authors focused on a premise that people have negative reactions to having little say in decision making process. They explored whether the statement holds true across different cultures and found that negative reactions towards little voice in decision making was more pronounced in low power distance countries like US and Germany compared to high power distance cultures like China and Mexico. Moreover, the study found that employees' perception of power distance within the same cultural setting has direct implications on work attitude and productivity (Brockner et al., 2001).

Farh, Hackett, and Liang (2007) conducted a power distance study on a pool of 163 supervisor-subordinate pairs across China, which is typically considered a high power distance culture. They looked into effects of both traditionalism and power distance into perceived organizational support and work outcomes, finding that low power scores were strongly linked to higher productivity and perceived support (Farh, Hackett, \& Liang, 2007).

In a bid to explore viability of universal management approach across cultures Lee, Pillutla, and Law (2000) modeled employee empowerment and continuous improvement against cross cultural power distance. While finding that 
continuous improvement in the work place had positive implications across all sampled cultures, study also found that empowerment could be positively or negatively correlated with job satisfaction across different cultures (Lee, Pillutla, $\&$ Law, 2000).

Similar links between empowerment and cultural background were also reported by Eylon and Au (1999). Authors found that among their $135 \mathrm{MBA}$ student participants, people with low power distance cultural background were more satisfied with their job when they were empowered. The exact opposite was true for people from high power distance cultures (Eylon \& Au, 1999).

Finally, Basabe and Ros (2005) explored the correlation between Hofstede's power distance index and two cultural dimensions such as Individualism-Collectivism and Hierarchy. Authors noted that power distance index and collectivism can often be correlated with other indices like social development HDI index, income difference Gini index, socio-political corruption index, and competitiveness index. The study found that most Protestant societies tend to be individualistic; Confucianist societies are more collective, while Islamic societies tend to be hierarchical. Most importantly, authors highlighted that power distance as well as the alternative social indexes can be quite accurate in quantifying the social preferences within any given community (Basabe \& Ros, 2005).

On the other hand, obtaining Hofstede's power distance index for a given community can be costly and time consuming. One would typically conduct extensive surveys on statistically representative samples, which could take anywhere from months to years to accomplish.

In this paper we investigated the correlation between the power distance and the vocabulary used in public speeches. For that purpose, we analyzed public addresses of leaders from nine countries around the globe, and a verbal index was derived which correlates to power distance index proposed by Hofstede.

\section{Methodology and text analysis}

We believe that cultural preferences influence not only our perceptions of the outside world but also our behavior, work patterns, and most importantly speech and choice of words. In fact, Zaharna (1995) indicated how cultural preferences are reflected in communication patterns across cultures. In particular, the author explored the importance of emphasis and function, affect and accuracy, image and meaning in both American and Arab cultures (Zaharna, 1995). Somewhat similar cross-cultural comparative study was conducted by Eslamirasekh (1993). The author analyzed speech patterns of American and Persian undergraduate students and found that Persian speakers used significantly more alerters, supportive moves, and internal modifiers compared to American speakers. This speech pattern preference was interpreted as a compensation for a degree of directness (Eslamirasekh, 1993). Many similar studies by Wolfson (1981), Scherer (2000), Blum-Kulka \& Olshtain (1984), and Anderson (1988) confirm that cultural preferences have direct impact on the speech patterns of cultural group representatives. Therefore, we would like to explore whether we can find patterns within the choice of words of representatives from different cultures.

For that purpose, we analyzed recent transcripts of public speeches delivered by leaders of different countries, and speeches were of similar length with an average of 3642 words. We chose countries that represent a wide range of power distance indexes within Hofstede's framework, and selected speech transcripts that are readily available online (Table 1). In these talks, speakers typically addressed a general public or a group of subordinates. Therefore, each speech can be reflective to supervisor-subordinate relationship within the culture, and hence can potentially shed light into the measure of power distance in the community.

Table 1. Public speeches by world leaders selected for analysis

\begin{tabular}{cccc}
\hline Speaker & Country & Year & Topic \\
\hline John Key & New Zealand & 2016 & $\begin{array}{c}\text { Prime Minister's Statement to } \\
\text { Parliament }\end{array}$ \\
\hline David Cameron & UK & 2015 & $\begin{array}{c}\text { Opening Speech to the House of } \\
\text { Commons }\end{array}$ \\
\hline Angela Merkel & Germany & 2015 & Statement to the European Parliament \\
\hline Tony Abbott & Australia & 2010 & Address to the Sydney Institute \\
\hline Barack Obama & USA & 2016 & State of the Union Address \\
\hline Nursultan Nazarbayev & Kazakhstan & 2015 & Annual State Address \\
\hline Alexis Tsipras & Greece & 2015 & Speech on Referendum \\
\hline Xi Jinping & China & 2015 & Address to the American Public \\
\hline Pranab Mukherjee & India & 2014 & Address to Both Houses of Parliament \\
\hline
\end{tabular}

We carefully analyzed speech patterns of different leaders around the globe and noted that certain words were used 
more frequently by leaders of countries with low power distance indexes, while leaders of high power distance states gave preference to a distinctly different group of words. Therefore, in each of the speech transcripts we looked for specific words and phrases, we classified them into two groups. The first group consisted of words like "I", "state", "call on", "entrust", and "must", which we called high power distance words for the purpose of this paper. The second group had words "we", "together", "people", "public", and "nation", which we named low power distance words.

Cumulative number of uses of high and low power distance words were noted for each speech. The ratio of the low power distance word count divided by the count of high power distance words resulted in the verbal index for each speech transcript.

\section{Correlation to Hofstede's power distance index and implications to Kazakh business discourse}

We find that the verbal indexes across different cultures show trends similar to Hofstede's power distance index (Table 2). Countries like New Zealand, Germany, and USA, which are traditionally associated with low power distance indexes, got low verbal index scores. At the same time countries with traditionally high power distance indexes like India and China got high verbal index scores as well.

Table 2. Verbal index results for cultures explored in this paper

\begin{tabular}{ccc}
\hline Country & Verbal Index & Hofstede's Index \\
\hline New Zealand & 0.06 & 22 \\
\hline UK & 0.47 & 35 \\
\hline Germany & 0.16 & 35 \\
\hline Australia & 0.74 & 40 \\
\hline USA & 0.23 & 60 \\
\hline Greece & 0.65 & 68 \\
\hline China & 0.48 & 77 \\
\hline India & 0.88 & not available
\end{tabular}

There are however a few notable exceptions in Table 2. UK and Australia scored closer to the higher end of the verbal index, while both countries have low power distance. Moreover, China scored unexpectedly low on the verbal index. These discrepancies can be explained by the biases associated with an individual delivering each speech and minor differences in target audiences. These discrepancies can be alleviated as more public speeches are analyzed and more verbal index data becomes available.

Furthermore, it is very interesting that after plotting Hofstede's power distance indexes against verbal indexes for all countries in Table 2, we obtain nearly linear relationship between the two. This is a remarkable finding, considering the simplicity of the method for calculating the verbal index. This finding confirms that indeed cultural preferences have significant influence on our verbal communication patterns, and therefore verbal communication patterns can be used as a reflecting measure of cultural preferences.

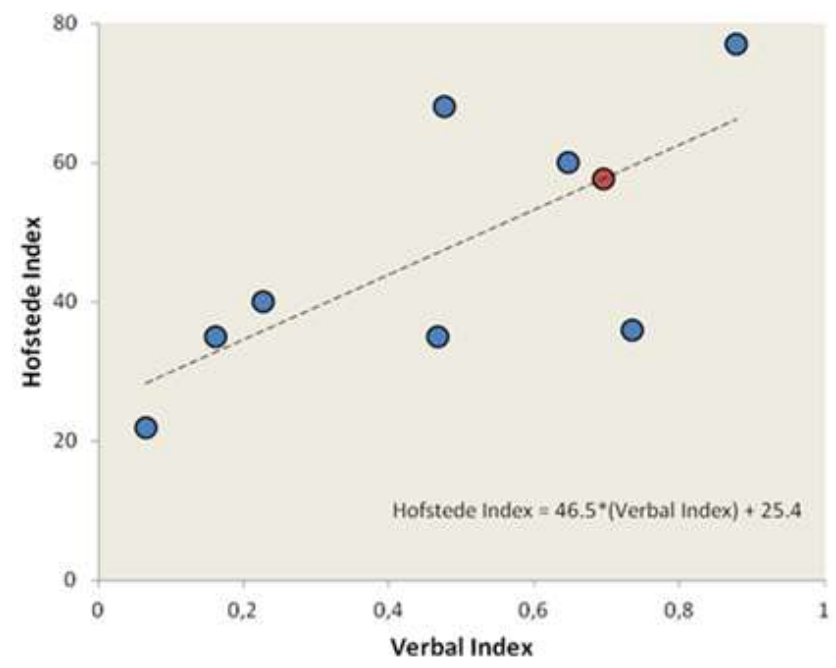

Figure 1. Correlation of Hofstede's power distance index to verbal index proposed in this paper. The red data point represents Hofstede's power distance index for Kazakhstan, which was estimated from the correlation 
To the best of our knowledge, Hofstede's power distance data is not available for any companies within Kazakhstan. The same holds true for many more developing economies across the globe. As a result, the verbal index, which is easily derived, can be used as an easier alternative for estimating power distance index. Unlike the power distance studies, which require large number of participants in questionnaires, verbal index can be calculated from public speeches easily available online.

In fact, after analyzing Kazakhstan's president's most recent state address (Table 1), we obtained the verbal index of 0.70, which is reported in Table 2. Using the linear correlation derived in Figure 1, we deduct that Kazakhstan would score about 58 points on Hofstede's power distance index. This groups Kazakhstan close to countries with high power distance preferences. This finding is in fact consistent with previous studies considering collective cultural affinity (Karibayeva \& Kunanbayeva, 2016) and business meeting preferences (Karibayeva \& Kunanbayeva, 2015) within Kazakh community.

\section{Kazakh Business Preferences Survey}

In addition to estimating Kazakh power distance index, we conducted a survey with 133 respondents to explore qualitatively cultural preferences of Kazakh business community. Survey participants represented a wide range of industries with $52 \%$ from the public sector and $48 \%$ from the private sector, while $26 \%$ of the participants represented management in their companies.

First, a definition of the power distance index was provided to participants, and they were asked to qualitatively rank Kazakhstan on power distance. Overwhelming majority of the participants assigned either high or median power distance index to Kazakhstan, which is consistent with our findings in Figure 1.

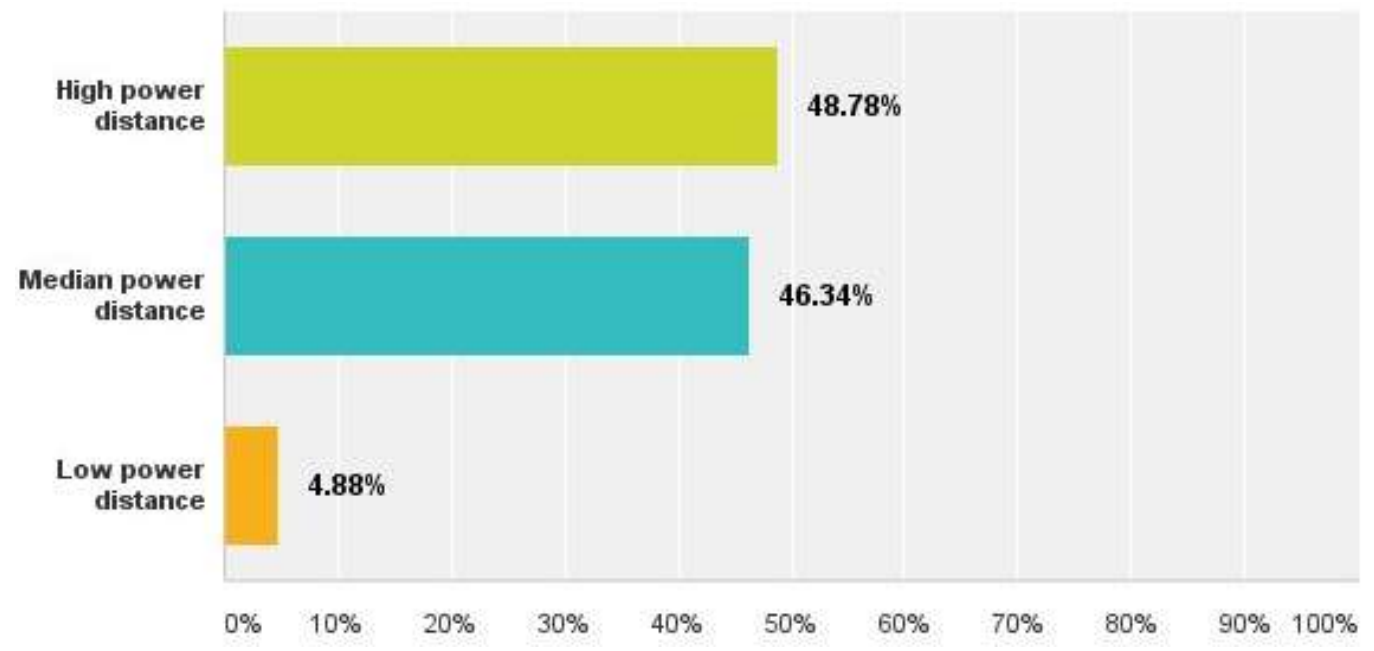

Figure 2. Qualitative assessment of Kazakhstan's power distance index by survey participants

Furthermore, it was previously argued that Kazakhstan shares many attributes common to the collective cultures (Karibayeva and Kunanbayeva, 2016), which results in predictable preferences within the work place. For example, vast majority of our survey participants admitted to consider heavily public opinion and maintaining "face" when making major personal or business decisions. Ninety-nine percent of people agreed on importance of building trust and personal relationships with business partners, and fifty-one percent of survey participants socialize with their coworkers regularly. While in the individualistic business cultures dropping by the office space without appointment is not encouraged, 63\% of our survey participants do not mind the practice. At the same time, Kazakh business community places a significant emphasis on having personal space at work compared to other collective cultures. Seventy-three percent of survey participants stated that it is important for them to have private work space (either cubical space or separate room).

Another important aspect that needs to be taken into account in any business culture is the directness of messages in speech or writing. While majority of western cultures prefer direct messages and often start communication with main objectives, eastern cultures typically include significant amount of background information and context before approaching the main target of their message. In fact, in majority of eastern cultures opening with the main objective can be viewed as abrupt or even rude. We asked our survey participants if they would consider a letter impolite if writer approached the main subject of the letter early in the message, and got mixed responses. While thirty-eight percent of participants felt that direct messaging would be impolite, sixty-two percent preferred the direct approach.

Business meetings and negotiations are important components of any business discourse. Conducting them is an art of its own, which becomes even more complicated within a multicultural environment. Kazakhstan has over a hundred of ethnical groups present. Moreover, since Kazakhstan obtained its independence in 1991, the presence of western businesses and investment within the country has been steadily growing. As a result, majority of the business meetings and negotiations in Kazakhstan are multicultural in nature. Fifty percent of the survey participants stated that cultural misunderstanding can be an issue in Kazakh business meetings. Participants outlined trust, respect, and consideration of cultural values as key factors to consider while hosting business partners. When it comes to business negotiations, majority of the survey participants acknowledged that age and rank of the counter party members affect their 


\section{perceptions.}

\section{Implications of Cultural Affinity on International Trade}

Hofstede's power distance can be viewed as an indicator of how similar business cultures are across the borders. One can argue that people are more likely to engage in business with cultures they understand better. There are a number of studies that elucidate the link between cultural affinity and likelihood of cross-cultural business engagement.

Davidson reviewed the role of country characteristics on direct foreign investment. In particular, he looked at corporate experience levels and found that smaller inexperienced firms have higher preference for near, similar markets compared to firms with broader international experience (Davidson, 1980).

Iwasaki and Suganuma focused on a single market and found similar trends to Davidson's work. They analyzed the data of Russian trade with 23 OECD member countries. Direct investment and socio-cultural similarity were found to be determining factors in determining trade volumes (Iwasaki and Suganuma, 2013).

Let us consider the historical dynamics of Kazakhstan's international trade in the light of the findings from the above studies. In particular, we will consider a set of data on Kazakhstan's top exporting destinations from 1992 to 2014 (Simoes and Hidalgo, 2011). After becoming an independent state in 1991, for the first few years Kazakhstan established Japan, South Korea, Turkey, China, Germany, and US as its main trade partners. These countries scored 54, 60, 66, 68, 35, and 40 accordingly in Hofstede's power distance gradation (Hofstede, 2001). It is quite interesting that four out of the six countries have very similar power distance index to Kazakhstan. Even though, cultural similarity is definitely not the only determining factor in the choice of trade partners, the data in Figure 2 shows that there can be a strong link between cultural affinity and likelihood of establishing business connections.

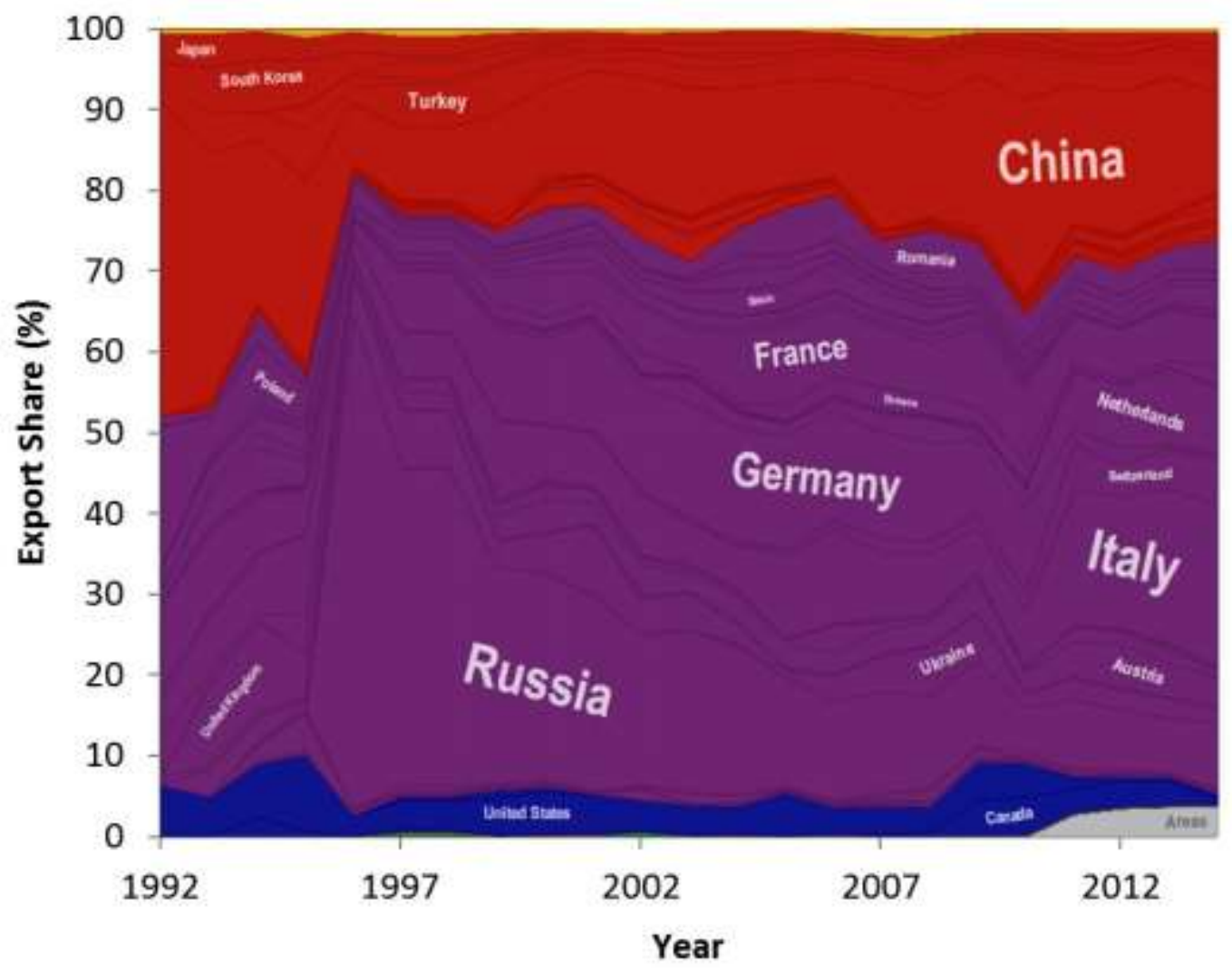

Figure 3. Historical evolution of Kazakhstan's top exporting destinations. The share of Kazakhstan's export destinations are plotted from 1992 to 2014 (adopted from Simoes and Hidalgo, 2011)

At the same time, major social-economic changes within the community can induce changes in cultural preferences. Since Kazakhstan removed itself from the Soviet Union, it has been strongly influenced by influx of western culture and investments. The effect of major political changes on cultural preferences of post-soviet states was explored in a study by Daller and Yildiz. The authors found that even though major political and socio-economic events lead to changes in power distance relationships at work, the changes are very slow due to significance of local cultural values (Daller and Yildiz, 2006). Therefore, eventual growth in export share of western destinations in Figure 2 can be explained by increased cultural awareness of western businesses and accumulated experience in trade within Kazakhstan. Even then, four (China 68, Italy 50, France 68, Turkey 66) out of six top exporting destinations in 2014 have a close power distance index to Kazakhstan. These findings reinforce the importance of cultural awareness within business organizations.

\section{Conclusion}

Kazakh business discourse is an emerging area for research, and the interest in the field is fueled by commercial interest within the country. Therefore, the need for understanding and exploring Kazakh business discourse and cultural 
preferences is of great value and importance. This paper presents a novel technique for estimating Hofstede's power distance index. Obtaining Hofstede's index is typically laborious and it requires collecting data from surveys with hundreds of participants. Verbal index on the other hand, can be easily obtained from publically available speeches delivered by representatives from different cultures. This data is readily available online, and therefore verbal index can be used to obtain. Hofstede's power distance index of 58 was obtained for Kazakhstan, an index previously unavailable in literature. This result is consistent with collective cultural affinity and business discourse preferences explored in previous studies.

\section{References}

Anderson, J. A. (1988). Cognitive styles and multicultural populations. Journal of Teacher Education, 39(1), 2-9.

Basabe, N., Ros, M. (2005). Cultural dimensions and social behavior correlates: Individualism-Collectivism and Power Distance. International Review of Social Psychology. 18(1), 189-225.

Blum-Kulka, S., Olshtain, E. (1984). Requests and Apologies: A Cross-Cultural Study of Speech Act Realization Patterns (CCSARP). Applied linguistics, 5(3), 196-213.

Bochner, S., Hesketh, B. (1994). Power distance, individualism/collectivism, and job-related attitudes in a culturally diverse work group. Journal of Cross-Cultural Psychology, 25(2), 233-257.

Brockner, J., Ackerman, G., Greenberg, J., Gelfand, M., Francesco, A., Chen, Z., Shapiro, D. (2001). Culture and procedural justice: The influence of power distance on reactions to voice. Journal of Experimental Social Psychology. $37,300-315$.

Daller, H., Yildiz, C. (2006). Power distance at work: The cases of Turkey, successor states of the former Soviet Union and Western Europe. Journal of Politeness Research. Language, Behaviour, Culture. 2(1), 35-53.

Davidson, W.H. (1980). The location of foreign direct investment activity: Country characteristics and experience effects. Journal of International Business Studies, 11(2), 9-22.

Eslamirasekh, Z. (1993). A Cross-Cultural Comparison of Requestive Speech Act Realization Patterns in Persian and American English. Pragmatics and Language Learning, 4, 85-103.

Eylon, D., Au, K. (1999). Exploring empowerment cross-cultural differences along the power distance dimension. International Journal of Intercultural Relations, 23(3), 373-385.

Farh, J., Hackett, R., Liang, J. (2007). Individual-level cultural values as moderators of perceived organizational support-employee outcome relationships in China: Comparing the effects of power distance and traditionality. Academy of Management Journal, 50, 715-729.

Hofstede, G. (1980). Culture's Consequences: International Differences in Work-Related Values. Beverly Hills: Sage.

Hofstede, G. (2001). Culture's Consequences - Second Edition: Comparing Values, Behaviors, Institutions and Organizations Across Nations. London: Sage

Iwasaki, I., Suganuma, K. (2013). A gravity model of Russian trade: the role of foreign direct investment and sociocultural similarity. Kunitachi, Tokyo, Japan: Russian Research Center, Institute of Economic Research, Hitotsubashi University, 40

Karibayeva, B., Kunanbayeva, S. (2015). Kazakh Business Discourse: Peculiarities of Kazakh Business Meetings. PEOPLE: International Journal of Social Sciences, 2(1), 1455-1462.

Karibayeva, B., Kunanbayeva, S. (2016). Intercultural Business Discourse: Characteristics of Kazakh Context. Proceedings of INTCESS2016 3rd International Conference on Education and Social Sciences, 154-157.

Lee, C., Pillutla, M., Law, K. (2000). Power-distance, gender and organizational justice. Journal of Management, 26, 685-704.

Scherer, K.R. (2000). A cross-cultural investigation of emotion inferences from voice and speech: implications for speech technology. In D. Guan, R. Zhang, B. Yua, T. Huang (Eds.), Sixth International Conference on Spoken Language Proceeding, ICSLP 2000/Interspeech 2000 (379-382). Beijing, China, October 16-20, 2000, Baixas, France: ISCA.

Simoes, A.J.G., Hidalgo, C.A. (2011). The Economic Complexity Observatory: An Analytical Tool for Understanding the Dynamics of Economic Development. Workshops at the Twenty-Fifth AAAI Conference on Artificial Intelligence.

Wolfson, N. (1981). Compliments in Cross-Cultural Perspective. TESOL quarterly, 15(2), 117-124.

Zaharna, R.S. (1995). Understanding cultural preferences of Arab communication patterns. Public Relations Review, 21(3), 241-255. 